\title{
Adapting PV for Various Applications
}

\author{
Bonna Newman, Arnold Biesbroek, Anna Carr, Josco Kester, Mark Jansen, Paul Sommeling, Jan Kroon, \\ Wilma Eerenstein
}

ECN Solar Energy, PO Box 1, 1755 ZG Petten, The Netherlands

\begin{abstract}
PV applications run from field installations, to building added PV to PV integrated into building, infrastructure and landscapes. Specifically, applications of integrated PV may demand very different properties of the PV panels, such as design, shade tolerance, resistance to harsh climatic conditions and the ability to capture light under non ideal conditions. However, the solar panels in production still mainly are 'one size fits all'. In this paper, ECN will present its developments towards utilizing the mass manufactured building blocks with novel module and system designs for increased application and usage.

Index Terms - silicon, BIPV, thermal testing, shade tolerance, bifacial modules
\end{abstract}

\section{INTRODUCTION}

PV panels based on crystalline silicon technology generally come in two sizes, 60 cells and 72 cells modules, with full or half-wafer sizes. The modules are made up of a glass front cover and a polymer based backsheet. Mechanical integrity comes from the aluminum frame. These modules are applied for field installations in all climates, and for building added applications.

For building and infrastructure integration a similar PV module is used, but without the frame to allow integration with the construction element. Each application demands a specific set of requirements resulting in a strong need for diversification and particularly optimization per application. To make these solutions more immediately available, the challenge is to take advantage of high volume solar cell manufacturing and diversify the end product for various applications.

In this paper, we examine a few specific challenges in integrated PV products, especially integrated concepts on buildings and infrastructure. We will discuss the impact on temperature and performance in a module integrated with standard building insulation; reducing the impact of partial shading with the TESSERA ${ }^{\mathrm{TM}}$ module concept that also allows more freedom of size and shape; and optimizing the yield of vertically installed PV bifacial modules for infrastructure integration.; . For each of these solutions, we combine modelling of performance and yield verified with indoor and/or outdoor tests to estimate both the size of the problem and the possible gain from design changes. For design, we use the building block of the six inch c-Si solar cell technology and look at adaptations, testing, characterization and modelling for safe, reliable integrated PV products.

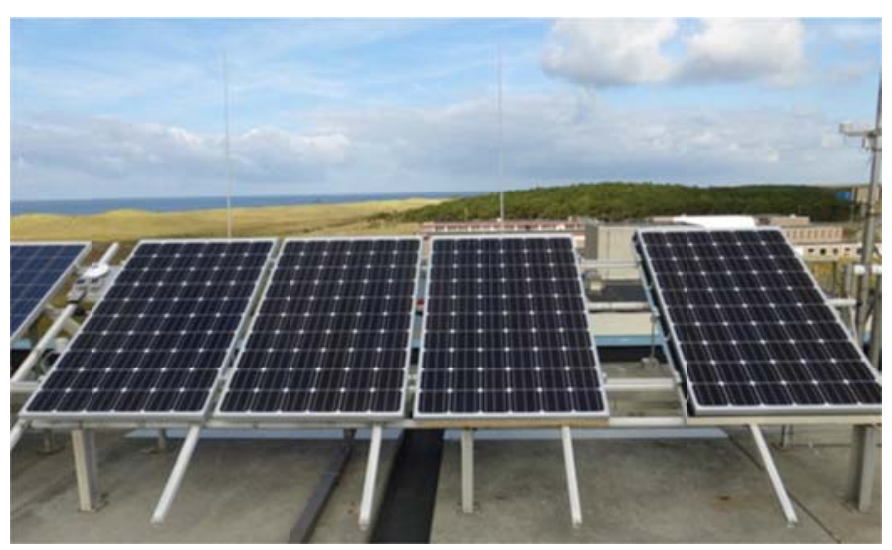

Fig. 1 Rooftop test setup for measurements used to develop and verify modeled predictions of module temperatures with various types of rear insulation. All module temperatures are measured on the backsheet along the horizontal line of symmetry.

\section{PV APPLICATIONS R\&D}

\section{A. Temperature aspects for integrated $P V$}

Integrating PV modules into an insulated building skin is expected to result in a higher PV operating temperature. Higher operating temperatures have a negative impact on annual electricity production, because of the negative temperature coefficient of the PV technologies, and potentially also on the lifetime of the PV modules. The exact effect will depend on location (irradiance, cloudiness, ambient temperature, wind speed) and installation (installation angle, presence of air gap or not, presence of nearby buildings). In order to develop a better model of performance in this case,

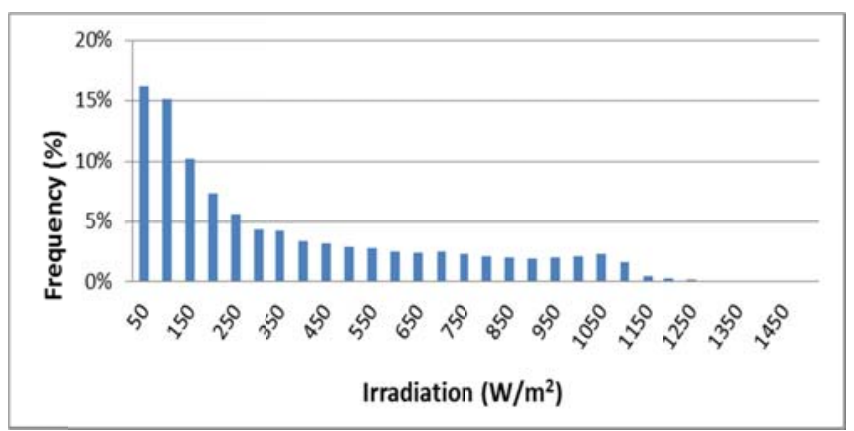

Fig. 2. Frequency histogram of measured irradiance data from ECN rooftop test setup in Petten, Netherlands. 


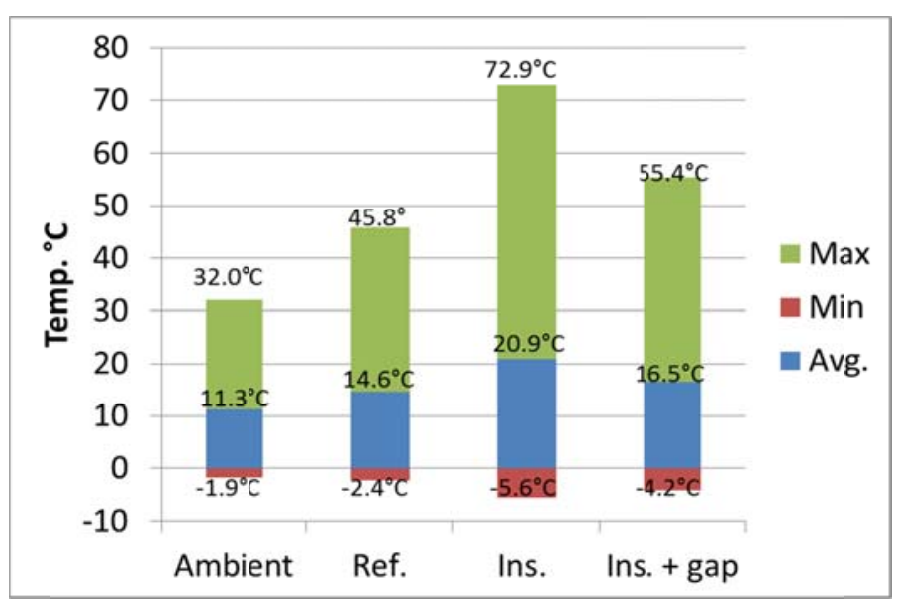

Fig. 4. Minimum, maximum, and average temperature measured from backsheet of modules or ambient environment from November 2014 to October 2015.

we established an outdoor test facility seen in Fig. 1. This facility is located on our rooftop in Petten, located in the north of the Netherlands near the ocean. The ECN outdoor test facility is described in more detail in [1] and [2]. The ECN outdoor test facility also includes a Mierij Meteo MW35 anemometer equipped with a MW36 wind vane to measure the wind speed and direction.

The test setup consists of three free standing, south-facing, rack-mounted $\mathrm{PV}$ modules of $270 \mathrm{Wp}$ each; 60 cells modules with mono-crystalline solar cells. The first module is the reference, typically installed free-standing module, with no insulation on the back side.

The second is a module fully insulated on the back with 60 $\mathrm{mm}$ of industry standard poly isocyanurate material, to simulate integration into the building envelope. The third module has an air gap of $2 \mathrm{~cm}$ between module and insulation (also $60 \mathrm{~mm}$ of poly isocyanurate), to test for the effect of a small ventilation layer behind the module. The setup is designed to ensure that the same environmental conditions are created for all the tested modules under investigation. We measure the temperature of each module in three locations along the horizontal center of the module.

The weather station measured solar irradiation (in plane and global horizontal), ambient temperature and wind speed. The weather data and PV module performance (IV tracing) were recorded every 10 minutes, and the modules are held at

TABLE I

SUMMARIZED WEATHER DATA.

\begin{tabular}{|c|c|c|c|}
\hline & Temp. $\left({ }^{\circ} \mathrm{C}\right)$ & Irr. $\left(\mathrm{W} / \mathrm{m}^{2}\right)$ & Wind $(\mathrm{m} / \mathrm{s})$ \\
\hline Avg. & 11.3 & 340 & 7.2 \\
\hline Min. & -1.9 & 10 & 0.0 \\
\hline Max. & 32.0 & 1459 & 29.2 \\
\hline$\sigma$ & 5.3 & 320 & 4.1 \\
\hline
\end{tabular}

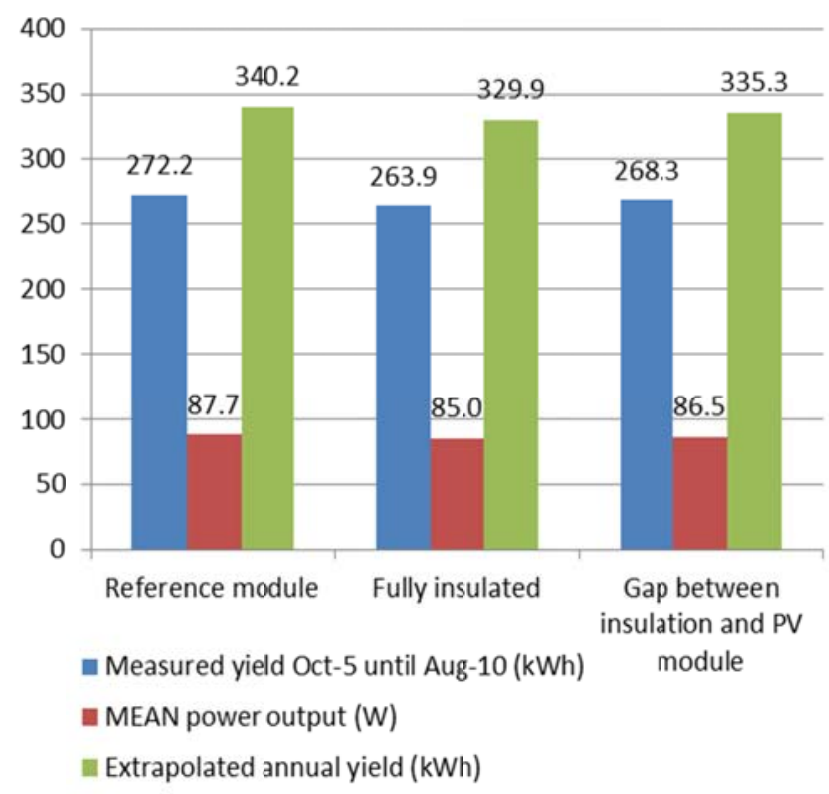

Fig. 3. Measured yield, mean output power, and extrapolated annual yield of three modules used in insulation experiment.

maximum power point between IV scans. Using the IV trace as performance parameter we ensure we are measuring the module performance directly. Data was logged when the irradiance level is higher than $10 \mathrm{~W} / \mathrm{m}^{2}$ from October 10 , 2014 through August 5, 2015.

The weather data collected during the 10 month period are summarized in Table I. For more detail, a histogram of irradiation is shown in Fig. 2. In this location, low irradiation is more common; $75 \%$ of all measurements are below 550 $\mathrm{W} / \mathrm{m}^{2}$.

In Fig. 4, we see the average, minimum, and maximum temperature of each module over the measured period. While the maximum temperature of the insulated module is more than $27^{\circ} \mathrm{C}$ higher, the average temperature is only $6.3^{\circ} \mathrm{C}$ higher. Also to note, due to the lack of data collection at less than $10 \mathrm{~W} / \mathrm{m}^{2}$ and the heat capacity of the whole system, the insulated modules can also be cooler than the ambient temperature. This may have impact on the inverter specifications for an insulated BIPV module, even in moderate climates. More detailed examination of the temperature data shows that $90 \%$ of the time the reference, insulated, and insulation plus gap modules operate at less than $25 \mathrm{C}, 30 \mathrm{C}$ and $40 \mathrm{C}$ respectively. We also observe that there is almost always a larger difference between the fully insulated module and the insulated module with a gap as compared to the latter and the reference module. This suggests that even a small air gap of $2 \mathrm{~cm}$ can provide a significant convective cooling effect.

Fig. 3 shows the average power output from each module, the total energy yield during the measurement period, and the 
extrapolated annual yield for all three modules. The energy yield of the insulated module is $3.1 \%$ less than the reference module. This corresponds well to the commonly used temperature coefficient for $\mathrm{c}$-Si modules of $0.5 \%$ per ${ }^{\circ} \mathrm{C}$ increase in operating temperature.

Assuming that the irradiance (I), wind speed (WS) and ambient temperature $\left(\mathrm{T}_{\mathrm{amb}}\right)$ are the key environmental variables for predicting the module operating temperature $\left(\mathrm{T}_{\mathrm{mod}}\right)$, we apply a multiple linear regression to the empirical data according to:

$$
T_{\text {mod }}=A+\alpha \cdot T_{a m b}+\beta \cdot I+\gamma \cdot W S
$$

Where $\mathrm{A}, \alpha, \beta$, and $\gamma$ are fitting parameters that will vary for each module and installation type. Results of the fitting are found in Table II. The linear fit results in a correlation coefficient, $\mathrm{R}^{2}$, greater than 0.88 the measured temperature and weather data for all three modules.

We note from this that the ambient temperature has a relatively small impact on differences in temperature. However, the difference in intercept suggests that the insulated module will on average operate at a slightly higher temperature. The insulated module is also more sensitive to irradiance and wind speed. In short, the yield of the insulated module is more dependent on the ambient weather conditions. However, even a small air gap behind the insulation can reduce this dependence.

We apply this same model to a situation where the irradiance is the same, but the ambient temperature is $2^{\circ} \mathrm{C}$ higher and there is no wind for cooling. We find that the difference between the yield of the fully insulated module and the free-standing module is only $3.8 \%$.

Therefore, we conclude, that in areas with low irradiance, insulation on the rear of c-Si BIPV modules only very moderately decreases annual yield of modules. This suggests that BIPV can potentially be implemented in these areas with similar cost models as building applied module technology, potentially increasing the market share of BIPV in northern, lower irradiance housing communities.

\section{B. Improving output under partial shading}

For large implementation of integrated PV modules into the built and infrastructure environments, it is also important to address issues of shade intolerance. It is well known that solar modules are sensitive to the presence of shade. Because of the series interconnection of all cells into three strings each string protected by a bypass diode, shade on one cell can cause the current produced by the other cells to pass via de diode instead of through the string and $1 / 3^{\text {rd }}$ of the module output is lost, see Fig. 5A. This also has implications on system level, as modules are usually connected in series as well. Solutions to minimize the power loss on system level are micro-inverters [3], power optimizers [4] and active
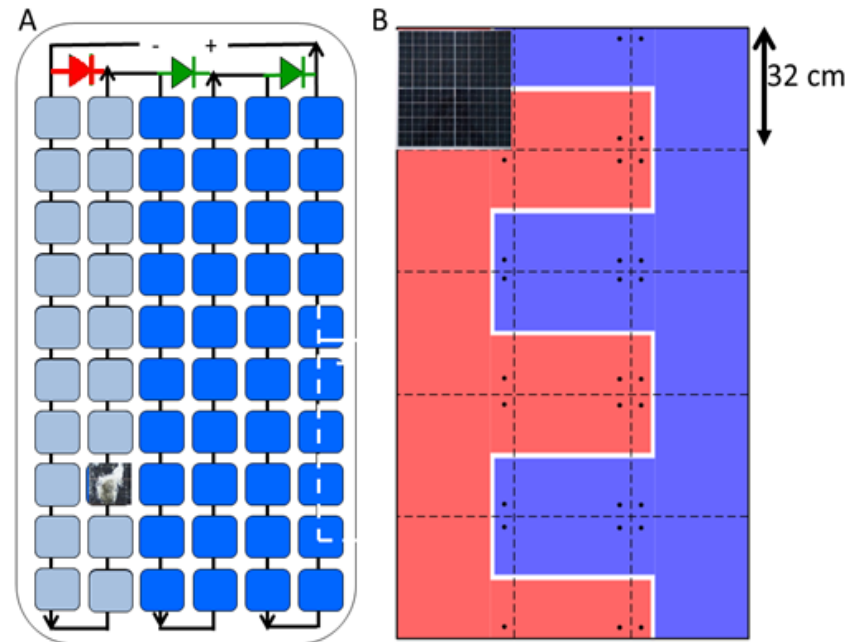

Fig. 5. A) conventional PV module consisting of 3 strings. Each string is protected by a bypass diode, and all cells are connected in series. In case of shading on one cell in the string, the current generated by the other cells will pass via de diode, shown as red. B) ECN shade tolerant module concept. Within each building block (top left corner of (B)), 64 mini-cells are connected in series and protected by diodes. The building blocks are then connected in parallel [7].

inverters [5]. ECN has developed an additional measure to lower shading losses, namely to redesign the electrical lay-out on module level. The solution consists of cutting the solar cells into 16 smaller mini-cells using a laser scribe and break process. 64 of these (equivalent to 4 standard cells) are connected in series, creating a building block delivering a Voc of $40 \mathrm{~V}$ and an Isc of $0.6 \mathrm{~A}$. These building blocks are then placed in parallel, resulting in a module voltage which is always $40 \mathrm{~V}$, and a current which depends on the number of building blocks used to construct the module, see Fig. 5B.

The solar cells used for these modules are so called back contact solar cells, which have both the positive and negative contacts on the rear side of the cell. The interconnection pattern is made in a conductive backsheet foil, and electrical contact between the cells and the foil is established using a conductive adhesive [6]. This allows very easy manufacturing, even when mini-cells are used - as each mini-

\section{TABLE II}

\section{RESULTS OF LINEAR REGRESSION FIT}

\begin{tabular}{|l|c|c|c|c|c|}
\hline $\begin{array}{l}\text { Module Temp. } \\
\text { Data }\end{array}$ & $\mathbf{A}$ & $\boldsymbol{\alpha}$ & $\mathbf{B}$ & $\boldsymbol{y}$ & $\mathbf{R}^{\mathbf{2}}$ \\
\hline reference & 0.83 & 1.05 & 0.0094 & -0.19 & 0.94 \\
\hline insulation & 1.75 & 1.07 & 0.0297 & -0.41 & 0.88 \\
\hline insulation+gap & 1.00 & 1.07 & 0.0161 & -0.28 & 0.90 \\
\hline
\end{tabular}


cell is placed on the foil with a pick-and-place robot. The combination of series and parallel connection within the

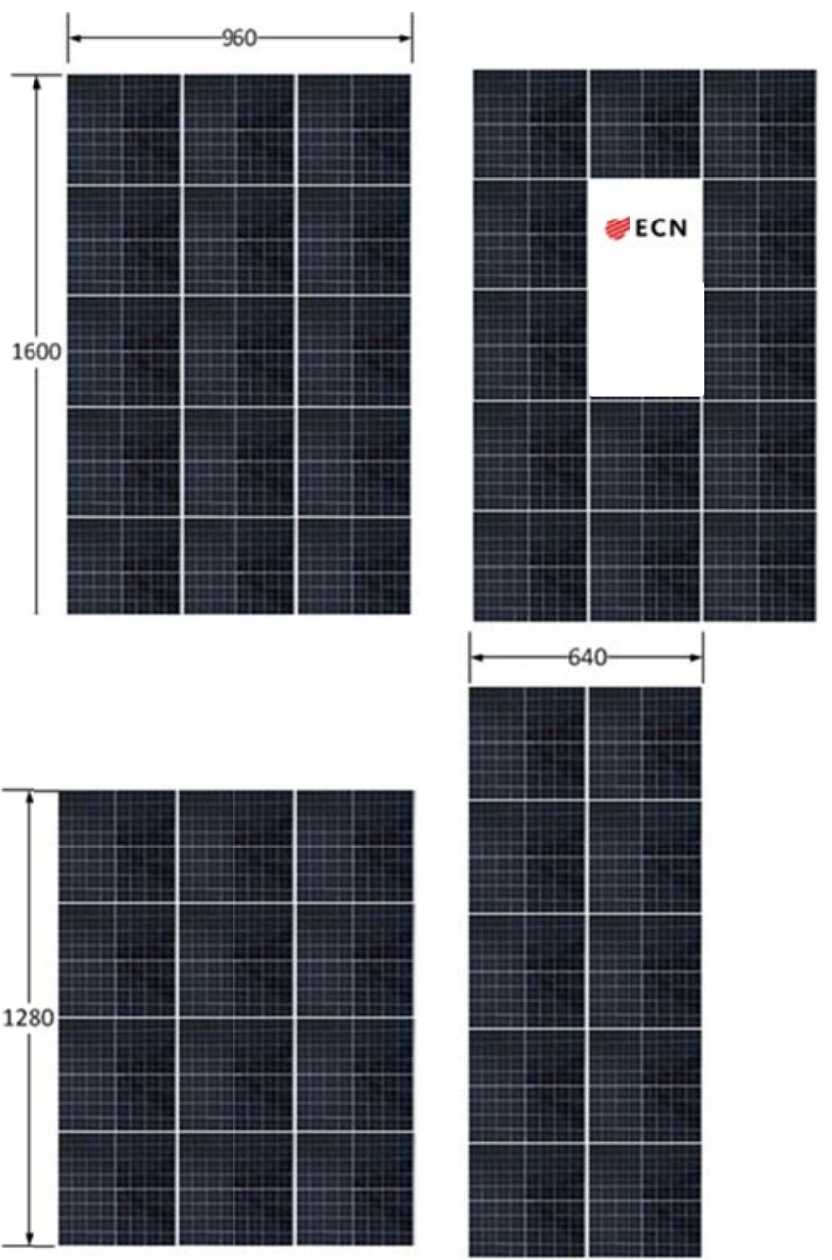

Fig. 7. Examples of novel module designs and different sizes and shapes. Dimensions are in $\mathrm{mm}$.

module is patterned into the foil.

The output of such modules has been measured under partial shading conditions, and these results have been used to predict annual yield improvement $[7,8]$. The measured shade linearity improved by up to a factor of 3.8 , depending on the shade situation, and the yield gain can be $4 \%$ for the modules alone.

The shade tolerant design has another distinct advantage. The output voltage is very constant, regardless of module size or presence of shade. This allows one dedicated microinverter for all module sizes.

This concept also allows easy adaptation for nonrectangular modules compatible with high throughput manufacturing. Some examples are shown in Fig. 7. Particularly for BIPV, but also for BAPV, the size and shape variations, as well as the different design can play an

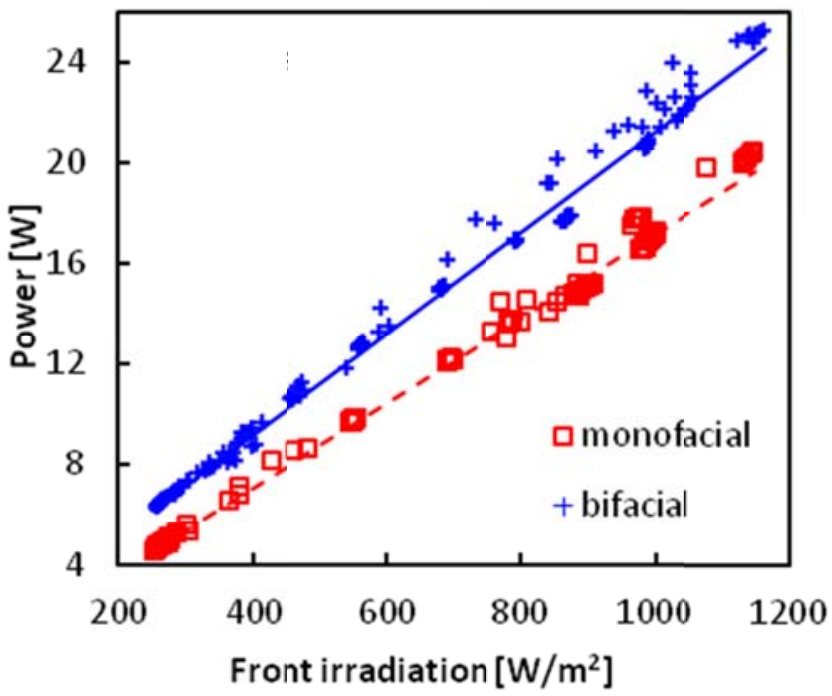

Fig. 6. Modelling vs. outdoor data of a vertically installed monofacial and bifacial modules, shows excellent agreement [9].

important role in improving aesthetics and increasing market acceptance of PV in/on buildings.

\section{Optimize yield of vertical PV using bifacial modules}

Facades and noise barriers often require vertical installation. This means the light incoupling is reduced, especially for locations closer to the equator. Optimally textured glass and anti-reflection coatings can greatly increase the energy output of vertically installed modules. However, due to variations during the year, predictive models are necessary to optimize total yield in these applications.

We have developed an energy yield model and calculator correlating the standard test conditions (STC) measurements to outdoor performance in various locations and at various orientations [9]. Initial application to bifacial modules with various albedo and orientations shows good agreement as seen in Fig. 6. The same toolbox has been applied to predict energy yield for modules with new types of textured glass, light trapping foils, and other module level light management solutions.

\section{SUMMARY}

Successful implementation of BIPV and BAPV systems requires not only novel module form factors but adaptation at the module level for predictability of reliability and performance of modules. In this contribution we have outlined a number of innovations that increase the diversity 
and reliability of using conventional PV c-Si cell technology for various integrated applications.

\section{ACKNOWLEDGEMENT}

This work is part of the PV Applications R\&D program at ECN Solar Energy, and receives funding from the Dutch Ministry of Economic Affairs and from the Dutch TKI program iDEEGO. In addition, the authors thank all the colleagues at ECN and industrial partners who contributed to the execution of this work.

\section{REFERENCES}

[1] Dekker N.J.J., ECN outdoor PV module test facility, http://www.sophia-ri.eu/fileadmin/ SOPHIA_docs/documents/Sophia_RI_description_Outdo or PV_module test_facility_-

[2] Dēkker N.J.J., Jansen M.J., Bennett I.J., Eerenstein W., Characterization of full size MWT back contact and $\mathrm{H}$ - pattern modules by outdoor IV-tracing measurements and explanations of the difference in energy yield, EU PVSEC proceedings 2012 3250-3253.

[3] Enphase, https://enphase.com/en-us

[4] Solaredge, http://www.solaredge.com/

[5] Sinapis et al "Outdoor Characterization of three PV architectures under clear and partially shaded conditions" 29th PVSEC

[6] I. J. Bennett, E. E. Bende, M.J.A.A. Goris and W. Eerenstein, An overview of developments in foil-based back-contact modules, 29th European Photovoltaic Solar Energy Conference and Exhibition, 2014.

[7] A.J. Carr et al, Tessera: Scalable, Shade Robust Module, 42nd IEEE Photovoltaic Specialists Conference, 2015.

[8] W. Eerenstein et al, TESSERA: MAXIMIZING PV YIELD PERFORMANCE WITH SIZE FLEXIBILITY FOR BIPV, 30th European PV Solar Energy Conference and Exhibition, 2015, p 2208

[9] Aken, B.B. van; Jansen, M.J.; Carr, A.J.; Janssen, G.J.M.; Mewe, A.A.; Relation between indoor flash testing and outdoor performance of bifacial modules. 29 ${ }^{\text {th }}$ European Photovoltaic Solar Energy Conference and Exhibition, 2014. 